Estudios Constitucionales, Año 9, No 1, 2011, pp. 13 - 36.

ISSN 0718-0195

Centro de Estudios Constitucionales de Chile Universidad de Talca

"Privacidad, trabajo y derechos fundamentales"

José Luis Ugarte Cataldo

\title{
PRIVACIDAD, TRABAJO Y DERECHOS FUNDAMENTALES ${ }^{1}$.
}

\author{
PRIVACY, WORK AND FUNDAMENTAL RIGHTS
}

José Luis Ugarte Cataldo

Profesor Derecho del Trabajo, Universidad Diego Portales.

jose.ugarte@udp.cl

RESUMEN: En este trabajo se sostendrá que la incorporación de la privacidad al interior de la relación laboral-como consecuencia del efecto horizontal de los derechos fundamentales-es un hecho relevante para los derechos de los trabajadores en general, pero que la introducción de la privacidad de la mano de una concepción dogmática amplia -entendiendo la misma no sólo como secreto sino también como derecho de autodeterminación - es un hecho, además, especialmente significativo para la sociedad en su conjunto, en cuanto vigoriza y aumenta el pluralismo y la disidencia social.

ABSTRACT: In this work it wil be supported that the incorporation of the privacy to the interior of the labour relation -as consequence of the horizontal effect of the fundamental rights-is a relevant fact for the rights of he workers in general, but the introduction of the privacy of the hand of a dogmatic wide conception -understanding the same one not only as secret but also as right of self-determination- is a significant fact for the society in her set, in all that it invigorates and it increases the pluralism and the social dissent.

PALABRAS CLAVE: Privacidad, derechos fundamentales, democracia, trabajador.

KEYWORDS: Privacy, fundamental rights, democracy, worker.

\section{LA FÁBRICA Y LOS DERECHOS FUNDAMENTALES DEL TRABAJADOR}

El ingreso, como lo dice una frase a esta altura canónica, de los Derechos fundamentales del trabajador a la fábrica es un hecho irreversible ${ }^{2}$. Pero es, antes que todo, un hecho especialmente subversivo.

Y no lo es, como podría creerse, por razones estrictamente jurídicas.

Nunca nadie dijo, al menos en términos formales del lenguaje del Derecho, que el trabajador no fuera el titular de esos derechos, ni que la empresa estuviera en un "mundo separado" del resto de la sociedad. De hecho, la doctrina del

\footnotetext{
${ }^{1}$ Artículo presentado el 23 de septiembre de 2010 y aceptado el 24 de noviembre de 2010.

${ }^{2}$ Nos estamos refiriendo, por si quedan dudas, a los denominados derechos fundamentales no laborales, esto es, aquellos cuya titularidad ejerce el trabajador en su calidad de ciudadano, tales como la intimidad o la libertad de expresión. En América Latina ha hecho fortuna, por influencia de la doctrina española, la expresión "derechos fundamentales inespecíficos", y en Chile en particular la expresión "ciudadanía en la empresa". Al respecto, ver Palomeque (1991). Recibido el 11 de febrero de 2010 y Aprobado el 24 de noviembre de 2010.
} 
efecto horizontal o entre particulares de los derechos fundamentales del trabajador se construyó sin reformas normativas relevantes como en Alemania, España, Chile 3 .

Otra cosa es que, en rigor, esos derechos no se ejercieran durante buena parte del siglo XX al interior de las empresas, pero eso ya no por razones jurídicas sino histórico-culturales. La empresa siempre fue entendida como un espacio típicamente privado, de fuerte connotación patrimonial, y la relación laboral como una vinculación entre particulares, y por tanto, sin espacio para derechos subjetivos como los fundamentales inespecíficos del trabajador -intimidad, libertad de expresión y otros- concebidos como técnicas de control propias de lo público. Por ello, como lúcidamente se escribía hace algunos años, "el trabajador, al atravesar la puerta de la fábrica, queda sometido a una ley propia y específica en la que se establecen preceptos obligatorios sobre su comportamiento en casa de su señor, de tal forma que la fábrica aparecía como una zona franca y segregada de la sociedad civil"4.

$\mathrm{Ni}$ tampoco es realmente revolucionario ese ingreso por razones técnico- jurídicas. Más allá de que nos gusten especialmente estos temas, las reflexiones del derecho laboral sobre este tipo de derechos no serán nada de novedosas en términos técnicos y jurídicos y se enmarcarán, en rigor, dentro de los caminos que otros -como la teoría del Derecho y el Derecho constitucional- ya caminaron.

Lo verdaderamente revolucionario de este ingreso es por razones políticas, en cuanto altera de algún modo tanto real como simbólicamente la distribución del poder en la relación laboral. Y eso es especialmente subversivo en sociedades como las latinoamericanas, donde, ya sea por la falta de poder sindical o por la falta de equilibrio en el sistema político y legislativo, el poder y el Derecho siempre estuvieron del lado de una de las partes 5 .

\footnotetext{
${ }^{3}$ En el caso alemán y el español, la justicia constitucional sostendrá, a principios de los cincuenta y ochenta, respectivamente, la aplicación de la eficacia horizontal de los derechos fundamentales en la relación laboral por razones básicamente especulativas: los derechos se aplican a los particulares, incluyendo empleador y trabajador porque corresponden a un orden objetivo de valores contenidos en el orden constitucional. En el caso chileno, curiosamente, esa idea será recepcionada por un órgano administrativo como la Inspección del Trabajo, la que comenzará a sostener a mediados de los noventa la citada horizontalidad de derechos fundamentales. Ver Lizama y Ugarte (1998).

${ }^{4}$ Baylos (1991), p. 95.

${ }^{5}$ En el caso chileno, la acción de amparo constitucional -el recurso de protección- no produjo en casi 30 años de existencia jurisprudencia alguna en materia de derechos fundamentales inespecíficos del trabajador. En rigor y sin dejar en el ámbito laboral la única y casi exclusiva jurisprudencia de protección es a favor de las empresas y en contra de la Dirección del Trabajo -por razones o de libertad de trabajo o de derecho de propiedad-. Es harto obvio que ello no se debió a que la empresa chilena fuera especialmente escrupulosa en el respeto de los derechos fundamentales del trabajador, sino que históricamente el legislador nacional nunca se preocupó de establecer ni normas sustantivas que establecieran dichos derechos ni procesales que le dieran cauces procesales efectivos a los mismos. Todo hasta la reforma procesal laboral de la Ley No 20.087.
} 
Cuando el Derecho decide que el trabajador tendrá un espacio o porción de la realidad que queda bajo la cobertura de la intimidad, entonces, el empleador ha quedado con un trozo menos de poder dentro de la relación laboral que lo vincula con ese trabajador.

Dicho de otro modo, antes del ingreso de esos derechos en ese espacio campeaba sin recortes la propiedad del empleador expresada en las denominadas facultades de dirección y mando. En términos simbólicos, cada centímetro que el Derecho le otorga a la privacidad del trabajador se la resta al espacio de la propiedad. Espacio que era, diríamos nuevamente en términos simbólicos, sagrado en Latinoamérica.

Ahí está, entonces -en la alteración de la distribución de poder-, la verdadera subversión de los derechos fundamentales del trabajador en las relaciones laborales, más que en la explosión de nuevos tecnicismos jurídicos -novedosa de todo punto de vista- de los juristas y laboralistas dedicados a estas cuestiones.

Ahora, desde la dimensión estrictamente jurídica, el cruce entre trabajo y privacidad impone dos cuestiones fundamentales para resolver: primero, cómo se va a determinar el contenido de ese derecho de cara a su ejercicio dentro de la empresa, y segundo, cómo se van a resolver los eventuales conflictos que ese ejercicio genere con los poderes del empleador.

Dicho de otro modo y parafraseando nuevamente la celebre expresión, si la intimidad va a ingresar a la fábrica quedan dos inquietudes centrales por responder: cuánta intimidad entra con el trabajador y cómo se arreglará el problema que ese ingreso provocará con la propiedad del empleador.

El primero, es el problema que técnicamente se denomina del ámbito protegido del derecho a la privacidad o de la delimitación del derecho. El segundo, es el problema de la solución de los conflictos entre ese derecho y el derecho -también fundamental- del empleador a decidir qué hacer en su empresa, ya sea que eso se encaje en la propiedad privada, como en Chile (artículo 19 número 24 de la Constitución), o en la libertad de empresa, por citar otras tradiciones jurídicas, como en España (artículo 38 de la Constitución) o en Perú (artículo 59 de la Constitución de 1933).

\section{El ÁMBITO PROTEGIDO CON EL DERECHO A LA PRIVACIDAD:} CUÁNTA PRIVACIDAD

La primera piedra en el camino, en ese sentido, es la obvia acerca de lo que se quiere decir con intimidad o privacidad.

La clásica distinción entre concepto y concepciones nos ayudará a ilustrar el punto. Existe casi un consenso en decir como concepto, que la privacidad 
es aquel espacio que una persona legítimamente quiere mantener alejado del conocimiento del resto. Y suele distinguirse, a continuación, en palabras de Garzón Valdés, la intimidad -espacio de "los pensamientos de cada cual, de la formación de las decisiones, de las dudas que escapan a una clara formulación, de lo reprimido, de lo aún no expresado"- de lo privado - "ámbito de los deseos y las preferencias individuales". El primero está protegido por la discreción y su velo corresponde develarlo sólo a su titular, el segundo está sujeto a las reglas de convivencia que el contexto cultural y social impongan ${ }^{6}$.

El punto es que desde ahí se construyen las más variadas concepciones sobre lo que debe quedar comprendido dentro de la privacidad, lo que explica quizás, el festín de definiciones sobre ese punto ${ }^{7}$.

En todo caso, más allá de la aparente pluralidad de ideas sobre lo íntimo y lo privado, resulta posible destacar dos grandes líneas de la reflexión y en algún sentido de la praxis jurídica, acerca de lo que dicho derecho debe reflejar.

Una posibilidad es entender como privacidad el derecho a un espacio vital cuyo acceso queda vedado para los otros, eso que se ha denominado derecho al secreto. Puestos en palabras de Carbonnier: "el derecho del individuo de tener una esfera secreta de vida, de la que tenga poder de alejar a los demás"

En ese espacio opaco al que el individuo tiene derecho, hay que precisarlo, caben numerosos aspectos de la vida: ideas y creencias religiosas, la vida sexual y amorosa, vida familiar, estado de salud, comunicaciones escritas u orales, la vida pasada del sujeto, orígenes familiares, estado civil, y en general, "todo dato, hecho o actividad personal no conocidos por otros, cuyo conocimiento por terceros produzca turbación moral o psíquica al afectado"”.

En algunas tradiciones legales, el contenido de la privacidad como secreto es complejo y abarca todos los aspectos de la vida privada bajo un solo derecho -como en Estados Unidos- y en otros - como en Chile, España o Perú- los distintos aspectos de la privacidad han dado lugar a diversos derechos, aunque todos interrelacionados: a la vida privada, la imagen, la intimidad, la inviolabilidad de las comunicaciones.

\footnotetext{
${ }^{6}$ GARZÓN (1999), pp. 9-11.

${ }^{7}$ Como lo describe Corral, por privacidad puede entenderse cosas tales como el derecho a ser dejado solo, el derecho a tomar decisiones personales, el derecho al control de la información personal, el derecho a la inaccesibilidad, el derecho a excluir a terceros de la información personal, el derecho sobre el acceso cognoscitivo. O todas ellas a la vez (nociones cuatripartitas) o parte de ellas a la vez (nociones tripartitas o bipartitas). Ver Corral Talciani (2000).

${ }^{8}$ Carbonnier (1965), p. 239.

${ }^{9}$ Novoa Monreal (1977), p. 46.
} 
La otra dimensión de la privacidad es entenderla, además, como autonomía. En este caso, como se ha destacado, corresponde al derecho a adoptar decisiones respecto de la propia vida sin la injerencia de terceros -derecho general de autonomía $-{ }^{10}$. Es, para decirlo en forma sencilla, el ideal del autogobierno.

Así, "cuando hablamos de privacidad pensamos, a un tiempo, en dos cosas, o que se nos excluya -según la fórmula de Sartre- de la mirada de los otros (privacidad como intimidad), o que, en cambio, nuestra voluntad cuente respecto de nosotros mismos y respecto de los demás y que nos constituya como sujetos (privacidad como autonomía)"11.

Por ello, mientras una exige opacidad, la otra supone todo lo contrario: visibilidad. Y en esa perspectiva, ambas dimensiones de la privacidad tienen sentido para el trabajador y sirven para moldear la relación entre ese derecho y el poder empresarial.

Mientras la privacidad como secreto le permite al trabajador mantener en la opacidad aspectos de su vida, denegando el acceso al panóptico empresarial, la privacidad como autonomía le permite al trabajador algo muy distinto: constituirse como sujeto propio y único, visibilizando su peculiar e individual percepción del mundo ante un espacio social tensionante a dicha visibilización, como es la empresa.

Para decirlo de un modo sencillo, que el empleador no intrusee el correo electrónico del trabajador es una exigencia de la privacidad -o del secreto de las comunicaciones, según corresponda- como espacio secreto; que el empleador deba respetar el modo que el trabajador diseña y modela como será visto en sus afueras -con aros, piercing o una barba al modo clásico o como miembro de una minoría sexual o cultural- deriva de la privacidad como autonomía.

Es evidente que de estas dos concepciones recién retratadas la cultura legal chilena ha girado en torno a aquella restringida que ve en lo íntimo y lo privado una especie de manifestación de la propiedad, a veces simplemente material, identificando el hogar con lo privado, a veces como espacio inmaterial, protegiendo zonas de la vida -como las comunicaciones- que deben quedar alejadas del conocimiento de terceros.

Y en este punto, de cara a la relación laboral cabe preguntarse: ¿qué concepción de las descritas acerca del contenido de la privacidad debe ser promovida para obtener mejor respeto y consideración para los trabajadores?

Aquí sostendremos que sí el derecho laboral contemporáneo ha decidido proteger -mediante la acción de tutela laboral, en el caso chileno en particular- el derecho

${ }^{10}$ PeÑa (2004), p. 78.

${ }^{11}$ PeÑa (1999), p. 70. 
fundamental a la intimidad y privacidad del trabajador ${ }^{12}$, entonces, los resultados de dicha operación de tutela estarán fuertemente condicionados por el tipo de concepción de la misma que se potencie, no siendo - para decirlo de otro modo-indiferente con qué tipo de contenido dotemos al derecho de la privacidad del trabajador.

En nuestra opinión, la concepción amplia vinculada a la idea de la privacidad como autonomía permite, tanto por razones teóricas como políticas, una mejor protección de la posición del trabajador frente a los riesgos que provocan los poderes del empleador.

Y no sólo eso. Diremos que el mejor costado de la protección de la intimidad para los trabajadores no se vincula con la concepción dominante en la cultura legal latina -la privacidad como secreto-, sino con la concepción de la intimidad como autodeterminación. En efecto, aquí sostendremos que si ya la incorporación de la privacidad al interior de la relación laboral -efecto horizontal de los derechos fundamentales- es un hecho relevante para los derechos de los trabajadores en general, la introducción de la privacidad de la mano de una concepción dogmática amplia-entendiendo la misma no sólo como secreto, sino también como derecho de autodeterminación- es un hecho significativo para la sociedad en su conjunto, en cuanto vigoriza y aumenta el pluralismo y la disidencia social.

En ese sentido, de partida cabe preguntarse: ¿existe apoyo teórico a lo que aquí hemos presentado como una atractiva opción político-jurídica de expansión de la privacidad del trabajador?, o de otro modo: ¿̨la concepción amplia que acabamos de describir -vinculando la privacidad no sólo al secreto sino también a la autonomía - es razonable como opción teórica en la aplicación de los derechos fundamentales más allá del atractivo político al que hemos hecho alusión y que explicaremos más adelante?

La respuesta es positiva. La opción de fijar un ámbito protegido extenso de la privacidad es especialmente coherente, desde el punto de vista teórico, con el modo de aplicación que progresivamente se ha ido imponiendo en la tradición jurídica para resolver los problemas a que dan origen la tensión entre este derecho -y en rigor, cualquier otro derecho fundamental del trabajador- $y$ los derechos y poderes constitucionales del empleador, la denominada ponderación de derechos ${ }^{13}$.

\footnotetext{
${ }^{12}$ Acción que protege los derechos constitucionales del trabajador frente a las conductas del empleador que los restrinjan de modo desproporcionado. Respecto de esta nueva acción laboral, ver UGARTE (2009).

${ }^{13}$ Más allá de las críticas y límites a que se ha sometido la ponderación o balanceamiento de derechos en la doctrina constitucional, cabe señalar que es difícil negar su enorme popularidad en el Derecho iberoamericano y particularmente en el Derecho chileno. Tanto el Tribunal Constitucional (Rol 1345-09) como la nueva judicatura de trabajo (Tutela 1-2008 Tribunal del Trabajo de Copiapó, caso Madrid con Sociedad Kronos Ltda.) han comenzado a utilizarlo como el modo de resolver las cuestiones difíciles a las que da lugar la colisión de derechos fundamentales. En el caso del Tribunal Constitucional, se señaló: "Que en consecuencia, aceptando
} 
La razón es sencilla: los derechos fundamentales que se ponderan son considerados restringibles $y$, por ende, su contenido nunca es definitivo o inderrotable, cuestión que supone que se les delimite ampliamente, a sabiendas de que podrán ser restringidos más tarde en un eventual conflicto con otro derecho fundamental.

Como señala Bernal Pulido: "el contenido de este ámbito de protección inicial está conformado por todo el espectro de normas y de posiciones jurídicas que sea posible relacionar en principio semánticamente con el derecho tipificado en la Constitución. Como tal, este vasto contenido ya constituye por sí una entidad jurídica. Esta adscripción prima facie se lleva a cabo con criterios muy laxos y se fundamenta en el principio in dubio pro libértate, según el cual, en caso de duda sobre un caso, éste debe considerarse como un caso relevante desde la óptica de los derechos fundamentales" 14 . Por lo mismo, dirá Alexy: "todo lo que presente una propiedad que -considerada aisladamente- baste para una subsunción bajo el supuesto de hecho queda tipificada, cualquiera que sean las otras propiedades"15.

En ese sentido, para ejemplarizar lo hasta acá sostenido: ¿̨es la apariencia externa del trabajador -como por ejemplo, el uso de la barba, aros o piercing- parte del derecho a la intimidad y vida privada?

La respuesta, al hilo de lo anterior, supone sostener que el ámbito protegido del derecho de intimidad abarca no sólo zonas espaciales de la vida (el hogar o las comunicaciones) o afectivas (relaciones familiares o sexuales) del trabajador, sino también espacios vitales de autonomía, como la apariencia externa del mismo, incluyendo el aspecto físico en sentido estricto, la indumentaria, los adornos y artefactos estéticos, etc. ${ }^{16}$

la tesis sostenida por el Instituto de Salud Pública, en el sentido de que el derecho de acceso a la justicia no sea absoluto y pueda tener que balancearse para que se alcancen otros derechos o fines constitucionalmente lícitos, como puede ser el de evitar la litigación infundada o puramente dilatoria, así como asegurar la eficacia de las sanciones administrativas y su imperio, no se sigue que el particular modo en que el precepto legal procura ese fin, resulte idóneo y proporcional y, por ende, justificado. La barrera de acceso a la justicia del Código Sanitario que se examina, consistente en la obligación de consignar la totalidad de la multa para reclamar, agrega poco, como se ha razonado, a la eficacia y oportunidad en el cumplimiento de la sanción. Rol 1345-09, del 25.05.2009.

${ }^{14}$ Bernal Pulido (2007), p. 310.

${ }^{15}$ Alexy (1993), p. 312.

${ }^{16}$ La jurisprudencia comparada, en este caso el Tribunal Constitucional español, así lo ha sostenido. El aspecto físico constituye "el primer elemento configurador" de la intimidad (STC 99/1994). De ahí que la doctrina afirme que "fuera de los casos de imposición de una indumentaria de trabajo, el trabajador es libre para adoptar cualquier apariencia externa o indumentaria en el trabajo. El hombre podrá llevar traje o vaquero, usar o no corbata, tener un pendiente, llevar el pelo largo, barba o bigotes, o mostrar un tatuaje o la insignia del sindicato. La mujer podrá vestir pantalón o falda, y llevar o no collares, pendientes o pulseras", GIL y GIL (2005), p. 223. En fin, precisamente por esto, la Corte de Casación de Francia ha sostenido que el hecho de que la apariencia externa del trabajador no sea del gusto del empleador es una causa que no justifica jurídicamente el despido (Cass. Soc. num. 96-42.326 de 1997). 
Y ¿qué ocurre si el empleador tiene buenas razones de higiene y seguridad para exigir o prohibir una indumentaria o artefacto estético determinado?

Eso ya no es un problema de delimitación del derecho de intimidad del trabajador, sino de su restricción por una eventual colisión de derechos fundamentales, cuestión que debe ser resuelta en la etapa de ponderación, la que explicaremos más adelante en este trabajo. En ese sentido, si la denominada ponderación o balanceo será, como parece ser, el modo en que los sistemas legales comenzarán a resolver los difíciles casos a que da lugar la aplicación de derechos fundamentales del trabajador que colisionan con los derechos fundamentales del empleador, entonces, la opción aquí retratada de una concepción amplia o extensa de la privacidad del trabajador es plenamente razonable y coherente.

Pero también, junto con las razones teóricas, hay razones político-jurídicas para optar por un contenido de la privacidad como autonomía en materia de protección de los trabajadores.

La razón de esto es que, si la intimidad y privacidad se entiende de un modo complejo y compuesto -tanto como derecho a la reserva y secreto como derecho a la autonomía-, entonces, no sólo opera como un límite al poder empresarial, sino que, además, puede proveer de un potente resguardo al pluralismo social, en el sentido del respeto a los modos de vida que cada uno desee sostener, particularmente los trabajadores. Pluralismo social que es, a todo esto, componente básico y nuclear de una sociedad política democrática.

Pero cabe ser un poco más explícito: ¿qué tiene que ver la democracia con mirar la privacidad de los trabajadores desde la autonomía?

La relación es fundamental, pero no evidente: las mejores teorías de la democracia contemporáneas la explican como un procedimiento deliberativo entre ciudadanos que concurren a esa deliberación pública y razonada sin sujeciones arbitrarias de terceros, lo que exige un espacio de constitución de la voluntad libre de interferencias arbitrarias o coacciones. Pues bien, ese espacio, precisamente, es el que nos ayuda a asegurar la privacidad como autonomía.

Ahí lo privado y lo público lejos de ser antagonistas se suponen uno al otro. Para ser ciudadanos activos en el proceso de debate público que supone la democracia requerimos de un espacio privado que nos permita constituirnos como sujetos dialogantes, que estén en condiciones de decidir cómo queremos presentarnos a nosotros y a nuestras ideas ante el resto. De ahí "la idea -sugerida por la experiencia griega- que lo público se soporta en lo privado y que, por lo mismo, el deterioro de lo privado acaba desmedrando lo público" ${ }^{17}$.

${ }^{17}$ Peña (1999), p. 71. 
Ahora, el tránsito de lo privado a lo público no se hace desde la nada, sino de un espacio comúnmente olvidado que es lo social. El sujeto que al amparo de la autonomía que la privacidad le asegura se construye a sí mismo no llega al espacio de la deliberación pública -la democracia- desde la nada. El sujeto transita desde lo privado a lo público mediatizado por una compleja red de espacios que lo tiene como actor, tales como juntas vecinales, grupos ciudadanos de la más variada índole, sociedades científicas como las que nos reúnen ahora, y por supuesto, la empresa y el trabajo, y en fin, todo aquello que constituye eso que se denomina espacio social.

Y ahí entonces, entre lo privado y lo público se cuela lo social. Y aparece con luz destellante la empresa por una cuestión que no es difícil de advertir: hay pocas dudas de que uno de los espacios sociales más relevantes para buena parte de las personas en las sociedades modernas es la empresa y la compleja red de relaciones que se construyen en torno a ella.

Y la pregunta surge, obvia, en ese punto: ¿cómo podrá un ciudadano construir y sostener en el espacio público de la deliberación democrática el discurso de la diferencia -en particular, de las minorías sexuales, religiosas, culturales- si en el espacio más relevante de las sociedades modernas -el trabajo- esas diferencias son reprimidas y sujetas a la coacción del empleador?

En ese punto, lo privado como un derecho de contenido amplio muestra toda su sutil relevancia: nos permite retirarnos hacia nosotros mismos, opacando a los ojos de lo público nuestro espacio íntimo, pero al mismo tiempo, nos permite volver sobre nuestros pasos para volcar hacia afuera eso que hemos construido y moldeado alejado de las miradas, mostrándonos como ciudadanos autónomamente constituidos.

Lo relevante de la privacidad, entonces, no es sólo que nos permite mantener alejados de las miradas del panóptico empresarial nuestros correos electrónicos, sino que nos permite mostrarnos tal como hemos decidido ser en un espacio social marcado por el poder autoritario, como es la empresa. Es aquí, a todo esto, cuando se esgrime la privacidad como autonomía, donde el trabajador se vuelva ciudadano propiamente tal.

Y ahí queda poco que agregar: en sociedades fuertemente autoritarias y homogéneas como las latinoamericanas, que un derecho fundamental-como el de privacidad- vigorice la diversidad y el disenso social y permita consecuencialmente refinar el pluralismo político y la democracia, es una muy buena noticia.

\section{El PROBlEMA DE LA COLISIÓN ENTRE DERECHO A}

\section{LA PRIVACIDAD Y LOS PODERES DEL EMPLEADOR}

Una vez fijado el ámbito protegido por el derecho de la privacidad o intimidad -ya sea en términos estrechos o amplios- queda una segunda cuestión, tan relevante como la primera: cómo se hace para solucionar aquellos casos donde 
este derecho del trabajador se encuentra cara a cara con facultades o poderes del empleador que corresponde, a su turno, a una parte del ámbito protegido de uno o más derechos fundamentales del empleador -como la propiedad.

Dicho de otro modo: cómo deberían resolverse los múltiples cruces entre parte de la realidad que se entiende corresponde a la privacidad o intimidad del trabajador -tales como correo electrónico, hábitos personales, opciones sexuales, etc.-, con las restricciones o eventuales invasiones que en el ejercicio de sus facultades podrían ser impulsadas por el empleador y que derivan de su condición de titular del derecho de propiedad o de la libertad empresarial.

Por supuesto, antes que todo, existe la posibilidad de que exista legislación que resuelva ese cruce. No tenemos noticia de que exista algo así -una normativa legal laboral que regule sistemáticamente el problema.

Y ante tal anomia legislativa, sólo nos queda encontrar la solución desde el texto constitucional. Y aquí, brevemente, existen tres opciones relevantes que, como es obvio, no provienen de la dogmática laboral, sino de la teoría constitucional que intenta responder acerca del modo más razonable para solucionar este complejo tipo de problemas. En el mercado de las ideas constitucionales existen varias posibles respuestas a una colisión entre derechos fundamentales:

La primera respuesta y en algún sentido más obvia, es negar el conflicto o colisión. Esta posición -un tanto optimista- sobre el asunto y muy popular en la tradición jurídica latinoamericana, pasa por sostener que cada derecho tiene un ámbito protegido o contenido fijo y definitivo, y que entre ellos existe una suerte de armonía simétrica, dada por la correcta delimitación de uno respecto del resto de los derechos fundamentales. En este sentido, se afirma que "los supuestos usualmente planteados como colisión entre derechos o entre derechos y bienes constitucionales, son en realidad seudo colisiones, no debiendo ser resueltos a través de la ponderación de bienes, sino por la vía de esclarecer interpretativamente o delimitar el contenido del derecho que se trate"18.

De este modo, la intimidad o privacidad del trabajador "encaja" perfecta y simétricamente con la propiedad del empleador, de modo tal que, habiendo un problema sobre el punto, sólo corresponde aplicar el adecuado método jurídico interpretativo para saber de qué lado está la situación o porción de la realidad que ha dado lugar al litigio: de la vereda de intimidad o de la vereda de la propiedad del trabajador, nunca de ambas al mismo tiempo.

En Chile, algo de esta postura se detecta en la jurisprudencia administrativa de la Dirección del Trabajo sobre el correo electrónico (Dictamen 260-19-2001):

${ }^{18}$ Serna y Toller (2000), p. 65. 
"De acuerdo a las facultades con que cuenta el empleador para administrar su empresa, puede regular las condiciones, frecuencia y oportunidad de uso de los correos electrónicos de la empresa, pero en ningún caso podrá tener acceso a la correspondencia electrónica privada enviada y recibida por los trabajadores. La razón de lo anterior corresponde a la naturaleza de comunicación privada protegida constitucionalmente que este Servicio le reconoce al correo electrónico de los trabajadores".

Leída en clave de teoría constitucional, lo que ese órgano de aplicación del derecho laboral está sosteniendo es algo así como lo siguiente: el contenido del correo del trabajador es siempre y en todo caso parte de la privacidad -o inviolabilidad-del mismo, no pudiendo en ese espacio o porción de la realidad operar el derecho de propiedad. El contenido del correo nunca queda como parte de la propiedad del empleador, y en consecuencia, nunca podrá existir el conflicto entre derechos.

El límite entre ambos derechos está perfectamente delineado: cuando se intenta transitar desde la determinación de la forma o modalidad en que se usa el correo, cuestión que está del lado del ámbito protegido de la propiedad del empleador, hacia la revisión del contenido del correo electrónico, cuestión que está ya dentro del ámbito protegido de la privacidad del trabajador.

No hay ahí espacio para ninguna colisión de derechos entre empleador y trabajador, porque los límites de cada derecho pueden ser delimitados con perfecta simetría entre ellos. Es obvio que esta tesis se conecta directamente con la que antes denominamos teoría estrecha del contenido protegido.

Los problemas de esta tesis son variados: primero, cuesta creer que sea posible determinar con exactitud el contenido definitivo de un derecho fundamental, especialmente, supuesto que se trata de normas de principios -y no de reglas- cuya estructura es esencialmente abierta e indeterminada.

¿Cómo determinar exactamente y para siempre de qué lado de cada derecho está cada una de las situaciones, posiciones o intereses que se protege con la privacidad y con la propiedad, respectivamente?

Es posible que exista pleno acuerdo en el núcleo de un derecho, pero esa seguridad se desvanece según nos alejamos hacia la periferia del contenido del Derecho. En el caso de la privacidad, pocas dudas caben que, por ejemplo, la vida sexual del trabajador es parte relevante de su contenido, pero es obvio que no habría tanta seguridad para sostener que la vida comercial o los antecedentes criminales son parte de ese contenido. Sobre todo, si una vez que lo ubicamos dentro del derecho respectivo, ese contenido deviene en definitivo e inderogable.

Segundo, aun cuando eso se lograra y tuviéramos derechos perfectamente delimitados, eso no impide que existan conflictos con otras normas constitucionales de derechos, ya que tal como señala Martínez, "disponer de normas perfectamente 
delimitadas no significa que éstas tengan que encajar perfectamente como las piezas de un puzzle, puesto que pueden suponerse unas con otras" ${ }^{19}$. Nada impide, entonces, desde el punto de vista lógico, que a pesar de lograr tener las normas de derechos fundamentales quirúrgicamente delimitadas, éstas entren en conflicto y sea necesario revisar cómo se resuelve la tensión entre ellas ${ }^{20}$.

En efecto, podemos decir, como veíamos lo hace la Dirección del Trabajo en Chile, que el contenido de un correo electrónico es parte de la vida privada y no del derecho de propiedad del empleador. Pero ¿qué ocurre si el correo es el de la empresa?, y más aún, ¿qué ocurre si es el personal del trabajador, pero a resultas de su revisión el empleador, advierte el robo o la pérdida de información estratégica de la empresa?

Aunque nunca haya sido explicitado históricamente en la cultura legal latinoamericana, una especie de variante de esta tesis es la que dominó - de facto- las relaciones laborales en sociedades como las latinoamericanas: entre la vida privada -y en rigor, entre todos los derechos fundamentales inespecíficos del trabajadory la propiedad, no existían conflictos porque ambas nunca se encontraban. La empresa como espacio de fuerte connotación patrimonial -amparado por el sacro derecho de propiedad- no era lugar para ejercer derechos como la privacidad o la intimidad de los trabajadores, más bien todo lo contrario: al ritmo de la cadena fordista autoritaria de trabajo nadie tenía derecho a la opacidad de la que provee la privacidad.

Las dos restantes tesis suponen reconocer la existencia genuina del conflicto entre principios constitucionales que establecen derechos fundamentales y en este caso, entre privacidad del trabajador y propiedad o libertad empresarial del em-

\footnotetext{
${ }^{19}$ Martínez (2007), p. 190.

${ }^{20}$ Pareciera que la libertad de expresión del trabajador perfectamente delimitada no incluye proferir las injurias o insultos, y que por tanto, insistimos bien delimitada, nunca podría colisionar con la honra del empleador. Ésta a su turno, incluye el derecho a no ser objeto de expresiones injuriosas. Ambos derechos están perfectamente delimitados respecto de una conducta del trabajador como es injuriar al empleador. No hay posibilidad, según esta tesis, de colisión. Pero, cabe preguntarse: ¿es eso realmente así? ¿¿Y qué ocurre si el trabajador molesto por un reciente accidente del trabajo o por el no pago reiterado de sus remuneraciones insulta al empleador? Esa acción de qué lado queda: de la libertad de expresión del trabajador o la afectación del derecho de la honra del empleador. La jurisprudencia chilena, aplicando el artículo 160 número 1 del Código del Trabajo, que justifica el despido por "injurias" del trabajador en contra del empleador, ha argumentado cosas como que "los hechos expuestos por el empleador para pretender fundamentar la aplicación de la causal invocada, expresados formalmente recién en el acto de contestación de la demanda, a juicio de estos sentenciadores y apreciando la prueba conforme a las reglas de la sana critica, no tienen intrinsecamente la gravedad suficiente para configurar la causal formal invocada dado que en los ambientes laborales rústicos, como corresponde a aquel donde el trabajador prestaba sus servicios, las expresiones que se han señalado como proferidas por él no tienen el disvalor laboral que podría sustentarse en otro tipo de ambiente laboral" (Corte de Apelaciones de La Serena, 23.02.2001, Rol 1930).
} 
pleador, aunque sea para entender que : a.) el conflicto es relativamente sencillo de resolver porque los derechos están jerarquizados, y b.) el conflicto es relativamente difícil, pero existe una solución razonable: la ponderación.

En el primer caso se encuentra la tesis que podríamos calificar de "optimista ingenua", de quienes junto con reconocer la colisión, creen ver una forma de solución sencilla y expedita que, en rigor, le quitaría dramatismo al problema. Esa fórmula simple de solución consiste en constatar la existencia de un orden jerárquico entre derechos fundamentales. En este caso, bastaría reconocer en qué ubicación se encuentran los derechos fundamentales en juego, para dar primacía al considerando más importante en el orden respectivo. Así de sencillo y expedito.

En Chile esta tesis ha sido sostenida, entre otros, por CEA, quien sostiene que "tiene que ser reconocida la disparidad de jerarquía entre los derechos esenciales, comenzando con el presupuesto de todos, o sea, la dignidad para proseguir con la vida e integridad personal", explicitando que ese orden jerárquico de prelación está conformado por "el derecho a la vida y la integridad personal, continuando por la intimidad, el honor y la inviolabilidad del hogar; siguiendo a la información y reunión; para concluir con el orden público económico, dentro del cual se hallan la libre iniciativa empresarial, la libre apropiabilidad de los bienes y el dominio ya adquirido o propiedad, en sus diversas especies" 21 .

La pregunta es obvia trasladada a nuestro problema: ¿qué derecho se supone que está primero en el supuesto orden de jerarquía abstracto de los derechos fundamentales: la privacidad del trabajador o la propiedad del empleador?

Se trata de una tesis muy difícil de aceptar tanto en términos científicos -no existe tal orden- como normativos -no debería existir tal orden- y con resultados prácticos absurdos ${ }^{22}$. De ahí que haya sido fruto de numerosas críticas; primero, es un orden intuitivo en cuanto no está nada claro el método ni la justificación de cómo se construye tal jerarquía ${ }^{23}$; segundo, encubre elecciones

\footnotetext{
${ }^{21}$ CEA (1999), p. 172.

${ }^{22}$ De hecho, tomársela muy en serio tiene resultados impresentables. Eso le ocurrió a la Corte Suprema chilena que en el tristemente célebre caso Impunidad Diplomática de Martorell -el libro de las fiestas dionisiacas entre empresarios y políticos en la embajada de Argentina-, donde se despachó con un ramplón considerando numerológico la compleja colisión entre derecho a la honra y vida privada vs. libertad de expresión: el primero está ocho números antes que el segundo, así que todo resuelto. Ver Luksic Craig y otros con Martorell Cammarella y otros. Revista Derecho y Jurisprudencia, T XC, 1993.

${ }^{23}$ Como explica RuIz-TAGLE, que llama a estas doctrinas "pontificias", esta postura es intuitiva, porque "no responde a un criterio de derecho positivo, sino que emana de una intuición; es lo opuesto a lo públicamente razonado", "asumiendo como propias doctrinas de origen pontificio o basadas en encíclicas papales". RuIzTAGLE (2001), p. 183.
} 
ideológicas evidentes -el orden de los derechos es un orden desde una ideología de los mismos- ${ }^{24}$; tercero, es un orden generalmente insuficiente ${ }^{25}$, y cuarto, produce un resultado práctico absurdo como es la devaluación total de ciertos derechos fundamentales -los del final del supuesto orden- que pasan a convertirse en "derechos cenicienta". Como explican Serna y Toller: "la tan manida jerarquía entre los derechos o no existe, o al menos no basta en la práctica para decidir la composición de un litigio. Una jerarquía cerrada implica no tomar en serio todos los derechos, porque algunos siempre quedarán diferidos en las controversias judiciales ante la presencia de otros de rango superior. Se generará así la grave injusticia de que los titulares de determinados derechos verán siempre sucumbir sus derechos en las litis donde se topen con quien detente un derecho abstracto superior en jerarquía" 26 .

La tercera y última opción, que comienza a gozar hoy de especial popularidad en nuestra dogmática latinoamericana, es entender que existen genuinas colisiones de derechos fundamentales -como la que precisamente se produce en diversos casos entre privacidad del trabajador y la propiedad empresarial-y que, además, existiría un modo razonable de solución de esas colisiones. Exige, eso sí, un modo de aplicar del derecho distinto al común -la subsunción- que la teoría constitucional denominada ponderación. La razón de ello es que se no se trata de aplicar reglas, sino principios entendidos como "mandatos de optimización" que ordenan hacer algo, a diferencia de las reglas, no de modo definitivo y determinado, sino en la mayor medida fáctica y jurídicamente posible.

Y si los derechos fundamentales son principios, entonces, se trata de derechos restringibles que tienen un contenido inicial -o a prima facie- que puede verse transitoriamente restringido si ese derecho colisiona con otro derecho fundamental.

\footnotetext{
${ }^{24}$ Como lo destaca Prieto SANCHIS, "como la decisión categoría de un grupo o una ideología que, desde una filosofía política homogénea, diseña un marco unívoco y cerrado" se trata más bien de lo que se ha dado en llamar una regulación principialista donde se recogen derechos sin especificar sus posibles colisiones, ni las condiciones de precedencia de unos sobre otros". Prieto Sanchis (2007), p. 218. Por ello, es difícil de aceptar que el orden propuesto - por ejemplo por CEA- sea un orden objetivo y racional, sino que, como es obvio, parecen expresar las personales preferencias ideológicas en la materia de sus redactores. Ello explicaría precisamente por qué a CEA se le olvida en su orden de prelación las "igualdades" como derechos fundamentales de los personas.

${ }^{25}$ Como explica CONTESSE, refiriéndose al orden de derechos de CEA, "si ese es el orden de prelación de los derechos fundamentales es claro que el listado que presenta es incompleto, pues sólo incluye los derechos contemplados en los numerales 1, 4, 5, 12, 13, 21, 23, 24 y 25 del artículo 19; eso es así, a menos que el autor considere que la libertad de conciencia (6), la igualdad (2), el debido proceso (3), la libertad de asociación (15), entre otros, no son derechos fundamentales". CONTESSE (2002), p. 78.
}

${ }^{26}$ Serna y Toller (2000), p. 26. 


\section{LA PONDERACIÓN Y LA PROPORCIONALIDAD COMO MODO DE RESOLVER EL} CONFLICTO PRIVACIDAD VS. PODERES DEL EMPLEADOR -PROPIETARIO.

La ponderación consiste en la asignación por parte del aplicador del derecho de peso o fuerza a un derecho fundamental por sobre otro derecho fundamental con el que se encuentra en conflicto, mediante el establecimiento de una jerarquía axiológica, cuya aplicación da como resultado que "un principio (el considerado superior en dicha jerarquía valorativa) desplaza al otro (u otros) y resulta aplicable" 27 .

Esa jerarquía axiológica fijada para solucionar un caso de conflicto o colisión de derechos fundamentales, sin embargo, no es permanente sino móvil: "el conflicto no queda resuelto de forma estable, de una vez por todas, haciendo prevalecer sin más uno de los dos principios sobre el otro, la solución del conflicto sólo vale para el caso concreto y, por lo tanto, es imprevisible la solución del mismo conflicto en casos futuros"28. Así, por ejemplo, en la colisión de derechos fundamentales que se produce entre la facultad de mando y control del empleador, derivada de su derecho constitucional de propiedad, colisiona con la intimidad del trabajador cuando aquél exige conocer los antecedentes criminales del trabajador.

Una primera vista del caso, llevaría quizás a sostener que el empleador no puede conocer dichos antecedentes del trabajador porque son irrelevantes para la prestación de servicios contratada -siendo su interés leve-, pero afectando seriamente un aspecto sensible de la privacidad de una persona -los errores del pasado-, debiendo ceder la propiedad a favor de la intimidad. Pero esa jerarquía es sólo móvil, depende del caso planteado y no es permanente: ¿qué ocurre si la función del trabajador es el cuidado de niños? Parece obvio que la jerarquía tenderá a invertirse: la intimidad cedería a favor de la propiedad ${ }^{29}$.

La ponderación, dicen sus partidarios, no es una actividad irracional del juez ya que se encuentra metodológicamente gobernada por el principio de proporcionalidad. Y éste, como señala ALEXY, puede ser explicado con una simple fórmula:

\footnotetext{
${ }^{27}$ Moreso (2000), p. 103.

${ }^{28}$ GuAstini (1999), p. 34.

${ }^{29}$ Esta es precisamente la solución adoptada, previa ponderación, por la Dirección del Trabajo en un caso similar: consultada por la Fundación Coanil sobre la posibilidad de exigir un certificado de antecedentes penales a sus trabajadores que cuidaban niños, y luego de reconocer la aplicación directa en esta materia de los derechos fundamentales a la no discriminación y a la intimidad del trabajador, señalaba que "el único caso en que debe admitirse como lícito la exigencia de un certificado de antecedentes corresponde a aquellas tareas o funciones que, por su naturaleza, exijan de modo indubitado, como parte de capacidad o idoneidad para su ejecución o desarrollo, la ausencia de antecedentes criminales o penales, que en el caso de la recurrente, queda restringido a las tareas del personal que tiene como función principal y directa la atención de niños o jóvenes con discapacidad, no pudiendo sostenerse dicha exigencia, en caso alguno, respecto de las restantes tareas o funciones desarrolladas por la fundación empleadora" (Dictamen No 3.840/194, del 18.11.02).
} 
cuanto mayor es el grado de la afectación de uno de los derechos en juego, tanto mayor debe ser la importancia de la satisfacción del otro.

¿Cómo opera el principio de proporcionalidad?

El principio de proporcionalidad, en su versión más sofisticada, implica la realización de tres juicios o sub-principios en el que se ha denominado "test alemán" ${ }^{30}$ : el de la idoneidad, el de la necesidad y el de la proporcionalidad en sentido estricto. Esto es, para decidir sobre la justificación de una restricción de un derecho fundamental (el del trabajador), que viene impuesta por el ejercicio de otro derecho fundamental (el del empleador), es necesario preguntarse, en orden transitivo, si dicha restricción es idónea, necesaria y proporcional.

El juicio de idoneidad exige que la restricción al derecho fundamental de que se trate permita alcanzar efectivamente un fin legítimo, entendiendo por tal, un fin o interés de naturaleza constitucional.

La idea relevante en este sub-principio es rechazar, por desproporcionadas, las medidas o conductas inidóneas del empleador ${ }^{31}$. Dicho de otro modo, el juez de tutela debería rechazar las medidas del empleador que persigan un fin constitucional legítimo - protección de derechos fundamentales propios o de terceros- cuando la medida o conducta no contribuye en forma relevante al fin inmediato buscado.

En uno de los primeros casos planteados en Chile sobre esta problemática, el denominado caso del polígrafo, fue la pretensión de una empresa aérea de "controlar el consumo y tráfico de drogas al interior de la empresa", por vía de someter a los trabajadores a un detector de mentiras, esta fue rechazada por la autoridad fiscalizadora por considerarla una medida no idónea e inconducente para el fin perseguido y que afectaba diversas garantías constitucionales del trabajador, entre ellas, la intimidad del trabajador.

\footnotetext{
${ }^{30}$ El principio de proporcionalidad es, en ese sentido, una exitosa construcción teórica alemana que constituye, en palabras de AleXY, el nudo gordiano de la ponderación, y que ha permitido justificar racionalmente la aplicación de normas que tienen el carácter de principios como las que establecen derechos fundamentales. Especialmente desarrollado por el Tribunal Constitucional alemán, que lo hace derivar de la "esencia de los derechos fundamentales", ha sido seguido por diversos órganos de justicia constitucional en el derecho comparado, como el español o el italiano. Por todos, ver Alexy (2008).

${ }^{31}$ En Chile es frecuente que los reglamentos internos de orden, higiene y seguridad, que por ley son de exclusiva confección del empleador, se encuentren plagados de medidas restrictivas de derechos fundamentales del trabajador que, en principio, no tienen mayor idoneidad para lograr los supuestos objetivos empresariales perseguidos: prohibición de tener relaciones sentimentales con compañeros de trabajo, prohibición de usar piercing o aros, exigencia de usar tal o cual corte de pelo, etc. La imaginación empresarial en Chile en esta materia es potente, la pregunta que debe hacerse desde la proporcionalidad es en qué sirven efectivamente estas medidas para lograr finalidades adscritas a derechos fundamentales del empleador. Si la respuesta es de nada, entonces, se trata de medidas no idóneas y por tanto, lesivas de derechos fundamentales del trabajador que deberían ser reprimidas por la acción de tutela.
} 
El Dictamen 684/50, del 06.02.1997, concluye que: "el uso del polígrafo aplicado a la selección de personal, así como a los trabajadores que actualmente se desempeñan en su empresa, para los fines de prevenir delitos, contrabando y tráfico de drogas y estupefacientes, es contrario al orden jurídico laboral chileno"32.

$\mathrm{Al}$ juicio de necesidad, por su parte, le importa que la medida o restricción del derecho fundamental sea indispensable para lograr el fin legítimo, no existiendo una alternativa más benigna con el derecho fundamental en cuestión. En ese sentido, será necesaria y proporcionada la conducta del empleador que restringe derechos fundamentales del trabajador sólo cuando no exista un medio menos gravoso de obtener el objetivo perseguido ${ }^{33}$. A veces este juicio parcial de la proporcionalidad ha sido también denominado como "principio de indispensabilidad", en el sentido de evaluar si la medida empresarial es indispensable para el logro de un fin empresarial legítimo.

En el conocido caso "deshuesador de jamones", un leading case del tema de los derechos fundamentales en España, la exigencia empresarial de que el trabajador

${ }^{32}$ Este caso, junto a otros como el control del peso, motivó que en la reforma laboral del año 2001 (Ley No 19.759) se incorporara una nueva norma legal sobre la materia -el artículo 154 del Código del Trabajo-, que establece expresamente la exigencia de idoneidad y necesidad para las medidas de control de los trabajadores: "en general toda medida de control, sólo podrá efectuarse por medios idóneos y concordantes con la naturaleza de la relación laboral y, en todo caso, su aplicación deberá ser general, garantizándose la impersonalidad de la medida, para respetar la dignidad del trabajador". Por otra parte, en un interesante caso, la Corte Constitucional colombiana tuvo que decidir si la decisión empresarial de modificar el turno laboral de una trabajadora, incluyendo ahora en su jornada laboral la prestación de servicios en día sábado, lesionaba su libertad religiosa atendido que su credo le impedía trabajar en dicho día. La empresa justificaba el cambio en que con dicha medida aumentaría "la productividad de la empresa" y "el sentido de pertenencia de los trabajadores a la misma”. La Corte consideró desproporcionada la conducta empresarial del cambio porque el "medio elegido no sólo no es necesario para llegar al fin propuesto, sino que puede ser contraproducente. Existen diversas formas de optimizar el desempeño de una empresa, diferentes al simple aumento de las horas que debe laborarse. De becho, el aumento no tiene necesariamente que hacerse a todos en el mismo horario del sábado, sin reparar en las diferencias entre los trabajadores, ya que una persona que se sienta violentada en sus convicciones religiosas, obligada a laborar un sábado no dedicará el pleno de sus capacidades, ni hará esfuerzos por mejorar la productividad. En este sentido la medida puede ser contraproducente. Respecto al otro fin mencionado por el director administrativo (generar sentido de pertenencia y mejorar el trabajo en equipo) considera la Sala que no es claro cómo puede conseguirse este objetivo al añadirse tres horas de jornada laboral adicional los días sábados. Antes bien, también podría llegar a ser una medida contraproducente" (T-982 del 2002).

${ }^{33}$ ALEXY señala que el juicio de necesidad y de idoneidad responde al ideal de la eficiencia u óptimo de Pareto. Eso no parece ser así, ya que el óptimo paretiano es aquel en que todos los sujetos ganan, sin que ninguno pierda, y aquí los trabajadores efectivamente pierden: ven restringidos sus derechos aunque en forma tolerable o razonable. En rigor, dichos juicios propios de la ponderación -el de la idoneidad y la necesidad- dicen relación más bien con la situación de "eficiencia de Kaldor-Hicks" o "mejora de Pareto", en donde los costos que soportan unos son menores que los beneficios que reportan otros, y éstos están dispuestos a compensar la pérdida. Precisamente, en los casos aquí analizados se presenta esa situación: los costos que soportan los trabajadores al ver restringidos sus derechos fundamentales se compensan por la ventaja que de ello obtenga el empleador siempre que ésta sea mayor que aquéllos. Sobre el análisis económico del derecho y los derechos de los trabajadores, ver UGARTE (2001). 
permitiera la grabación y difusión por televisión de su trabajo -cortar y trozar jamones ibéricos-, y que derivó en el despido del trabajador ante su negativa, fue considerada lesiva de su derecho a la propia imagen por innecesaria ${ }^{34}$. La razón, en palabras del Tribunal Constitucional: "los requerimientos organizativos de la empresa que pudieran llegar a ser aptos para restringir el ejercicio de aquéllos (al margen de los conectados de forma necesaria con el objeto mismo del contrato) deben venir especialmente cualificados por razones de necesidad, de tal suerte que se hace preciso acreditar -por parte de quien pretende aquel efecto- que no es posible de otra forma alcanzar el legitimo objetivo perseguido, porque no existe medio razonable para lograr una adecuación entre el interés del trabajador y el de la organización en que se integra" (STC 99/1994).

En un interesante caso en Chile, la Dirección del Trabajo efectuó este juicio de necesidad para rechazar la medida implementada por un empleador en el ejercicio de sus facultades derivadas de su propiedad sobre la empresa. La empresa que perseguía un fin legítimo, como es el mejor control del tiempo de trabajo, finalidad adscrita a su derecho de propiedad, decidió implementar un registro de control de tiempo de ida y de regreso a los servicios higiénicos de los trabajadores. Esa medida del empleador es idónea porque efectivamente permite controlar el tiempo de trabajo, pero no fue considerada necesaria: provoca una restricción del derecho de la intimidad del trabajador que no se justifica porque existen otros medios menos invasivos y más benignos con la intimidad de los trabajadores para controlar el tiempo de trabajo de los trabajadores ${ }^{35}$.

En el mismo sentido, recientemente, la Dirección del Trabajo evaluó un nuevo sistema informático de control de los trabajadores denominado WIN

\footnotetext{
${ }^{34}$ Como destaca PARDo FAlCon, con esta sentencia, "el TC deja a un lado los criterios que tradicionalmente había venido empleando a la hora de enjuiciar la constitucionalidad de las restricciones de que pueden ser objeto los derechos fundamentales del trabajador en el seno de la empresa para empezar a operar sobre la materia con otras técnicas expresamente concebidas por la ciencia del Derecho Constitucional cuando de tales derechos fundamentales se trata; técnicas que van a reforzar, además, la posición de éstos en ese específico marco contractual hasta el punto de erigirlos en verdaderos límites de los poderes jurídicos de que dispone el empresario como consecuencia de la relación laboral". PARDO FALCÓn (1997), p. 299.

${ }^{35}$ La argumentación -vía ponderación- de la Dirección del Trabajo, en Dictamen 4541/319, del 22.09.1998, señala que: "si bien es cierto el empleador empresa Costa S.A. tiene una amplia órbita de facultades para administrar su empresa -amplitud que es correspondiente con los atributos del derecho de propiedad de que es titular-, sin embargo debe tenerse presente que en un Estado de Derecho, el legítimo ejercicio de estas facultades de administración encuentra su justo límite en los derechos y garantías constitucionales que jurídica y valóricamente estén investidas de igual o mayor significación. En este sentido, al dejar establecido el artículo 19 No 4 de la Constitución Política de la República que asegura a todas las personas el respeto y protección a la vida privada y pública y a la honra de la persona y de su familia, se fija un límite a las facultades de administración del empleador -las que desde luego no deben interferir ni perturbar el ámbito personal y privado de sus dependientes- lo que a todas luces ocurre al pretender medir el tiempo de permanencia de los trabajadores en los servicios higiénicos".
} 
VNC, que permite el control a distancia de los computadores de los empleados, como si el empleador estuviese delante directamente del computador controlado. $\mathrm{Al}$ respecto, dicho organismo de fiscalización lo considera lesivo del derecho de intimidad del trabajador porque: "en virtud de este principio de proporcionalidad, se exige que la medida limitativa, en este caso el control por medio del referido programa computacional, sea la única capaz de obtener el fin perseguido, de forma tal que no exista otra forma de alcanzar dicho objetivo sin restringir el derecho o que fuese menos gravosa, lo que, en la situación en análisis, evidentemente no ocurre, ya que existen variadas otras formas que el empleador puede utilizar para controlar la prestación de los servicios y que son menos restrictivas de los derechos fundamentales del trabajador, especialmente en lo referido al derecho a su intimidad" (3441/072 del 20.08.08).

Por último, se utiliza el juicio de proporcionalidad en sentido estricto. Sólo si la restricción es considerada idónea y necesaria, corresponde, y sólo en ese caso, revisar si, además, es proporcional en sentido estricto.

Cuando, para el logro de una finalidad legítima derivada de un derecho fundamental, se requiere indispensablemente la restricción de otro derecho fundamental, de modo tal que la satisfacción de uno sólo puede realizarse a costa del otro, debe aplicarse el juicio de proporcionalidad en sentido estricto, que en los términos de Alexy puede expresarse, como ya lo habíamos adelantado, en la denominada ley de la ponderación: cuanto mayor sea el grado de no cumplimiento o de no satisfacción de un derecho fundamental, tanto mayor debe ser la importancia del cumplimiento del otro $^{36}$.

Esta operación supone tres pasos básicos; primero, determinar el grado de afectación o restricción de un derecho fundamental; segundo, determinar el grado de importancia del derecho que opera en sentido contrario, y tercero, deben compararse ambos para establecer si la importancia de uno justifica la restricción del otro. Para hacer operativa esta operación de asignación de peso, y por ende, permitir la comparación entre los derechos en colisión, ALEXY propone una escala tríadica de intensidad: grave, media o leve.

En el juicio de proporcionalidad en sentido estricto el derecho más importante, de acuerdo al juicio de valor de intensidad efectuado, atendido las premisas normativas y fácticas ya señaladas, desplaza al derecho menos importante para ese caso en concreto. Como lo ejemplifica Bernal Pulido: "la afectación de la vida y la salud de una niña, que se origina al permitir a los padres evangélicos no llevarla al hospital, podría catalogarse como intensa, dado el peligro de muerte; de forma

${ }^{36}$ AleXY (1993), p. 71. 
correlativa, la satisfacción de la libertad de culto de los padres, que se derivaría de dicha permisión sólo como media o leve" ${ }^{37}$.

Opera, entonces, el núcleo de la ponderación en sentido estricto: la comparación entre el grado de intensidad de la afectación del derecho fundamental, en nuestro caso del trabajador, con el grado de importancia del derecho fundamental en que se sostiene la conducta que genera la colisión, en nuestro caso del empleador. La finalidad de esa comparación es el establecimiento de la relación de "precedencia condicionada": de precedencia, porque un derecho desplaza la satisfacción del otro derecho, y condicionada, porque sólo vale para esa colisión en esas circunstancias en concreto.

En el caso "kronos", un caso inaugural de la nueva acción de tutela derechos fundamentales de la nueva reforma procesal laboral chilena, el juez del trabajo de la ciudad de Copiapó decidió que el despido fundado en la revisión de las conversaciones de messenger que habían quedado registradas accidentalmente en el disco duro del computador de la empresa, constituía un conducta lesiva del derecho fundamental de privacidad de la trabajadora. La razón era que se trataba de una afectación grave de dicho derecho que no se encontraba compensada por un interés relevante respecto del derecho de propiedad de la empresa, aun cuando dicha revisión le había permitido al empleador determinar que se había enviado documentación de su propiedad a una funcionaria de otra empresa.

Esta asignación de peso o importancia de los derechos colisionados, en todo caso, como ya advertimos, corresponde a una relación de precedencia condicionada o de jerarquía móvil, que se construye desde el caso concreto, y no tiene el carácter de absoluta o fija, porque nada impide que en otros casos se revierta la atribución de pesos utilizada y triunfe el derecho fundamental ahora derrotado.

\section{CONSIDERACIONES FINALES: LOS LÍMITES DE LA PROPORCIONALIDAD}

De todo lo hasta aquí dicho podemos señalar, al final, que la privacidad concebida en términos dogmáticos amplios - de la mano de un contenido protegido extensivo- tiene una función que va más allá de la protección de los intereses y bienes particulares de trabajadores afectados, y que dice relación con su capacidad para mejorar y aumentar el pluralismo social propio de una sociedad democrática.

Pero al mismo tiempo, entender la privacidad del trabajador en términos amplios aumenta las posibilidades de que dicho derecho fundamental entre en conflicto con derechos del empleador también fundamentales que concurren en la empresa

${ }^{37}$ Bernal Pulido (2003), p. 228. 
-como la propiedad o la libertad económica-, haciendo necesaria la utilización de la ponderación y la proporcionalidad como medio de solución de dichas colisiones.

Y ahí es necesario tener una especial dosis de realismo.

En efecto, la recepción de la ponderación y la proporcionalidad para resolver este tipo de cuestiones no deberían hacernos caer en un optimismo ingenuo, perdiendo la vista acerca de que no se trata de una fórmula "a prueba de errores", que nos provea en todos los casos de soluciones que unánimemente reconoceríamos como las mejores.

Lejos de eso, la apelación a la ponderación y balanceo entre derechos puede terminar en una fórmula retórica que encubra la arbitrariedad, si no estamos conscientes de sus límites:

No es un método científico de solución de controversias si por eso entendemos un método cien por ciento predictivo, que nos permita encontrar siempre y en todo caso, la única y mejor respuesta posible. Ese método no existe, por de pronto, en nada que tenga que ver con el Derecho.

Tal como se ha señalado críticamente, no existe un ponderómetro que mida objetivamente, para el caso que nos interesa, los grados de afectación que la conducta del empleador produjo en la privacidad del trabajador, por lo que es inevitable la valoración judicial de estas cuestiones. Pero ello no significa que se trate de un modo arbitrario.

Ello, porque no se trata de construir un orden cardinal de valores que pudiera expresarme en forma métrica sobre una medida común. Efectivamente, no existe un ponderómetro, sino el uso de una escala ordinal de valores, que se construye sobre apreciaciones cualitativas sobre el grado de afectación e importancia de los principios en juego, y a la que se les asigna sólo de modo metafórico una valoración de peso e intensidad.

Su fortaleza, a nuestro juicio, no es que nos provea de la respuesta correcta o científicamente correcta a estos problemas, que insistimos no existe, sino que nos permite superar el déficit argumentativo con que se suelen resolver estas cuestiones en nuestras tradiciones jurídicas.

Antes de que el juez chileno sortee el problema de la revisión del correo electrónico o de la exigencias de información personal o económica o sexual del trabajador, bajo la sencilla pero opaca fórmula de excluirlos, vaya a saber uno por qué vericueto interpretativo, del derecho a la vida privada o la inviolabilidad de las comunicaciones del trabajador, parece más razonable que nos diga para ese caso por qué la conducta del empleador ha de ser considerada idónea, necesaria y proporcionada.

Con esa sencilla explicación, en nuestra tradición, hemos ya ganado mucho. 


\section{BIBLIOGRAFÍA CITADA}

1. AleXY, Robert (1993): Teoría de los Derechos Fundamentales (Madrid, CEC), p. 312.

2. Alexy, Robert (2008): Teoría de los Derechos Fundamentales (Madrid, CEC).

3. BAYLos, Antonio (1991), Derecho del Trabajo: un modelo para armar (Madrid, Trotta), p. 95.

4. Bernal Pulido, Carlos (2003): Estructura y límites de la ponderación (Alicante, DOXA), p. 228.

5. Bernal Pulido, Carlos (2007): Refutación y defensa del neoconstitucionalismo (Madrid, Trotta), p. 310.

6. Carbonnier, Jean (1965): Derecho Civil, Tomo I (Barcelona, Bosch), p. 239.

7. CEA, José Luis (1999), El sistema constitucional de Chile: sintesis critica (Santiago, Universidad Austral), p. 172.

8. CONTESSE, Jorge (2002): Reglas y principios en Chile: :jerarquía entre los derechos constitucionales? (Valparaíso, Universidad de Valparaíso), p. 78.

9. Corral Talciani, Hernán (2000): Configuración Jurídica del derecho a la privacidad II: concepto y delimitación (Santiago, Revista Chilena de Derecho).

10. GARZÓn VAldés, Ernesto (1999): "Privacidad y publicidad" (Argentina, Revista Jurídica de la Universidad de Palermo).

11. GIL y GIL, José Luis (2005): Poder directivo y apariencia externa del trabajador (Valencia, Relaciones Laborales), p. 223.

12. Guastini, Ricardo (1999): Distinguiendo, Estudios de teoría y metateoría del Derecho (España, Gedisa), p. 34.

13. Lizama, Luis y UGARTE, José Luis (1998): Interpretación y Derechos Fundamentales en la Empresa (Santiago, ConoSur).

14. Martínez, David (2007): Conflictos constitucionales, ponderación e indeterminación normativa (Madrid, Marcial Pons), p. 190.

15. Moreso, Juan (2000): Conflictos entre principios constitucionales (España, Trotta), p. 103.

16. Novoa Monreal, Eduardo (1977): Derecho a la vida privada y libertad de información, Siglo (Santiago, XXI Editores), p. 46.

17. Palomeque, Manuel (1991): Los derechos laborales en la Constitución española (Madrid, Centro Estudios Constitucionales).

18. Pardo, J. (1997): "Los derechos fundamentales como límites de los poderes jurídicos del empresario", (España, Revista Española de Derecho Constitucional), p. 299. 
19. PeÑA, Carlos (1999): "Notas sobre las relaciones entre privacidad y autonomía", (Argentina, Revista Jurídica de la Universidad de Palermo), p. 70.

20. PeÑA, Carlos (2004): Informe sobre el proyecto de ley de protección al honor y la intimidad de las personas (Santiago, UDP), p. 78.

21. Prieto, L. (2007): El constitucionalismo de los derechos (Madrid, Trotta), p. 218.

22. Ruiz-Tagle, Pablo (2001): Una dogmática general para los derechos fundamentales en Chile (Santiago, Universidad de Chile), p. 183.

23. Serna, Pedro y Toller, Fernando (2000): La interpretación constitucional de los derechos fundamentales: una alternativa a los conflictos de derechos (Buenos Aires, Editorial La Ley), p. 65.

24. Ugarte, José Luis (2009): Tutela de derechos fundamentales del trabajador (Santiago, LegalPublishing)

25. Ugarte, José Luis (2001): Análisis económico del derecho: el Derecho del Trabajo y sus enemigos (Uruguay, Fundación de Cultura Universitaria). 
